\title{
RETRIEVAL OF PROJECTILE METALLIC FOREIGN BODY PENETRATING THE THYROID GLAND
}

Lohith Shivappa ${ }^{1}$, Nicola Baretto², Surender Kumar Morodia ${ }^{3}$

${ }^{1}$ Assistant Professor, Department of ENT, Subbaiah Medical College, Shimoga, Karnataka.

${ }^{2}$ Senior Resident, Department of ENT, Goa Medical College, Goa.

3Senior Consultant, Department of ENT, Asilo Hospital, Mapusa, Goa.

\section{ABSTRACT}

Penetrating neck injuries constitute 5\%-10\% of all trauma cases. Such injuries are dangerous because of the high risk of injury to the vital structures in the neck and hence demand an immediate surgical exploration. We present a case of a penetrating injury of the neck caused by the broken metallic fragment at work place.

\section{KEYWORDS}

Metallic, Fragment, Projectile, Thyroid, Retrieval.

HOW TO CITE THIS ARTICLE: Lohith Shivappa, Nicola Baretto, Surender Kumar Morodia. "Retrieval of Projectile Metallic Foreign Body Penetrating the Thyroid Gland." Journal of Evolution of Medical and Dental Sciences 2015; Vol. 4, Issue 98, December 07; Page: $16390-16391$, DOI: $10.14260 /$ jemds/2015/2425

\section{CASE REPORT}

A 36-year-old male patient, mechanic by profession presented to our Emergency Department with history of penetrating injury on the anterior aspect of his neck. The patient, a metal fitter, had been hammering on a piece of metal that shattered on impact. He was seen by local surgeon and an attempt was made to remove the foreign body under local anesthesia, failing which patient got referred here to Goa Medical College. On examination, patient was conscious and well oriented. He was haemodynamically stable and did not have any neurological deficit. Local examination revealed puncture wound of $1 \mathrm{~cm}$ situated $2 \mathrm{~cm}$ above medial end of right clavicle. There was surrounding neck swelling and tenderness. A CT scan of neck was performed, which revealed a radio opaque foreign body $6 \mathrm{~mm}$ within the right lobe of thyroid at the level of the seventh cervical vertebra Fig (a) and Fig (b). The patient was taken up for immediate surgical exploration under general anesthesia. A horizontal incision was given from right anterior border of the sternocleidomastoid to the opposite side, 2 fingerbreadth above suprasternal notch, encompassing the wound of entry and the neck was explored. The foreign body was embedded in right lobe of thyroid about $5 \mathrm{~mm}$ deep from the surface of gland. The foreign body was identified and removed Fig (c).

Haemostasis was achieved and the wound was closed in layers. There were no postoperative complications.

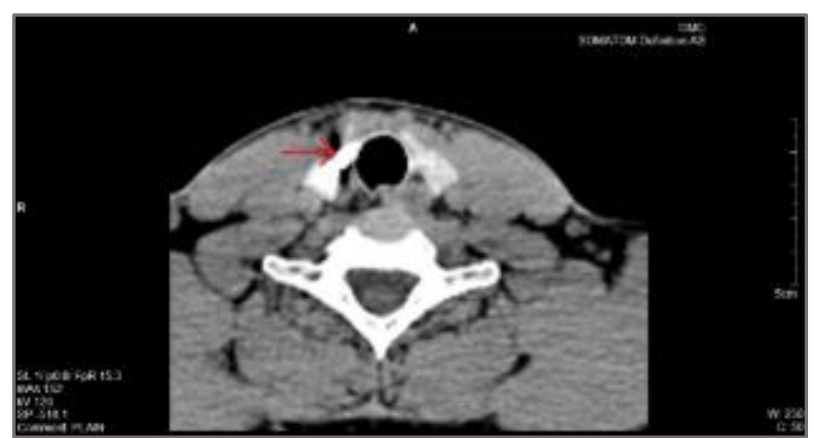

Fig (a)

Financial or Other, Competing Interest: None.

Submission 17-11-2015, Peer Review 18-11-2015,

Acceptance 30-11-2015, Published 07-12-2015.

Corresponding Author:

Dr. Lohith Shivappa,

H. No. S3, Teaching Faculty Quarters,

Subbaiah Medical College, Shimoga-577222.

E-mail: dr.shivappalohith@gmail.com

DOI:10.14260/jemds/2015/2425

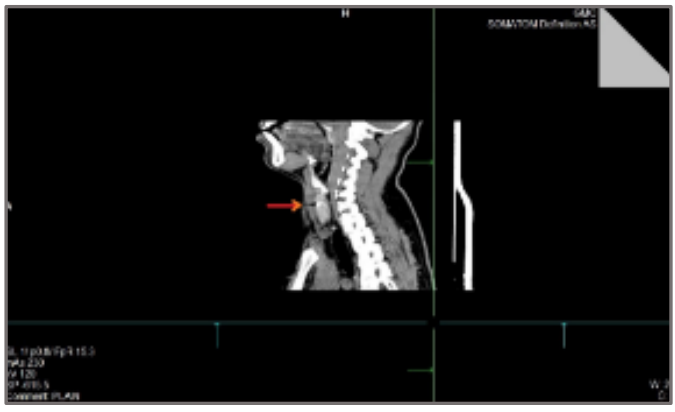

Fig (b)

Fig. (a) \& Fig. (b): Axial and Sagittal CT Scan of Neck showing Metallic Foreign Body in the Right Lobe of Thyroid.

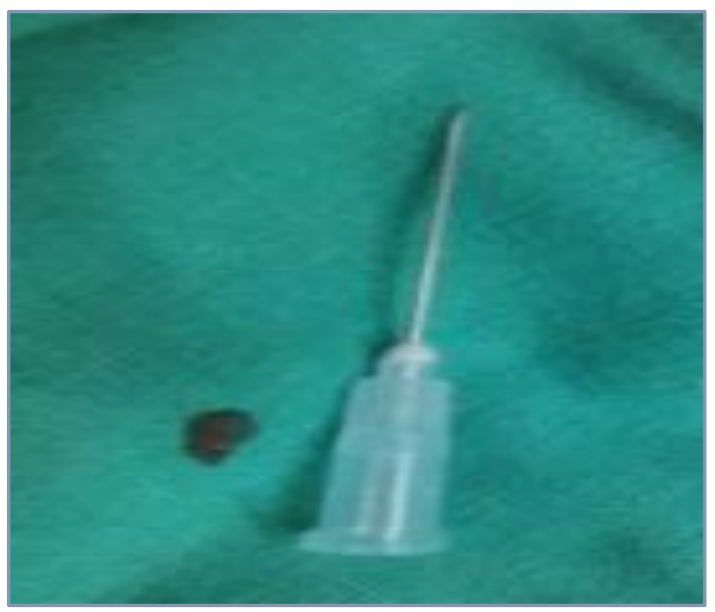

Fig. (C)

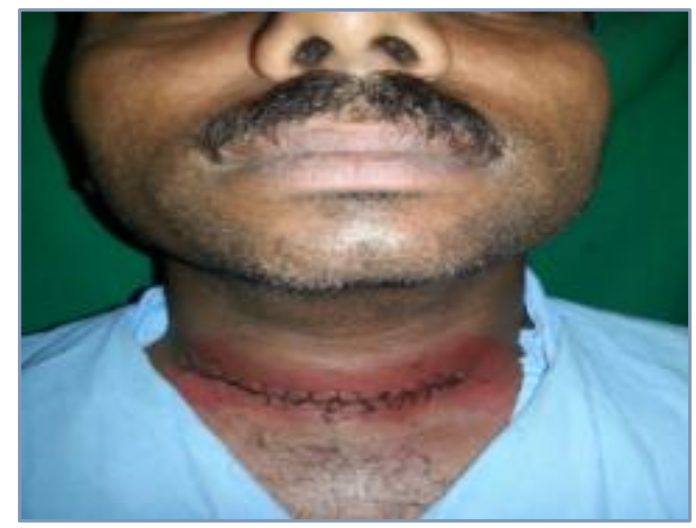

Fig. (d) Post op Day 3 


\section{DISCUSSION}

Penetrating neck injuries constitute $5 \%-10 \%$ of all trauma cases.(1) In the neck region there are vital structures such as the neurovascular bundle, the major vessels, trachea and the esophagus which are at risk and hence an early diagnosis and management is required.

When a projectile penetrates tissue it decelerates, but as it does so it dissipates energy, which is in the form of kinetic energy into the tissues. The amount of kinetic energy contained by the projectile is determined by this equation, $\mathrm{KE}=1 / 2 \mathrm{MV}^{2}$, where $\mathrm{M}=$ mass and $\mathrm{V}=$ velocity. Because the velocity is squared in the equation, the speed of the projectile is the most important factor in determining its level of energy.

A projectile with twice the velocity has four times the kinetic energy of the lower velocity projectile. Because energy is ultimately conserved, the energy contained by the projectile is transmitted into the tissues impacted. Therefore, high velocity projectiles can impart significantly larger amounts of energy into tissues. Projectiles decelerate as they travel through the air, but only $\sim 150$ to $170 \mathrm{ft}$./sec of velocity are required to penetrate the skin, so even though the size of projectile is small it had sufficient kinetic energy to cause the injury as in our case.(2)

Though the wound of entry could be inconspicuous as in our case making the injury look trivial, the foreign body can lodge into the vital structures of the neck and hence exploration becomes mandatory. The penetrating injuries should be managed in a systematic manner. Firstly, the patient's airway should be established and he should be made haemodynamically stable. Once this is achieved, a detailed examination should be done to assess the site and severity of the wound. Vascular injury should be looked for and should always be ruled out. The physical findings of vascular injury are pulse deficit, active bleeding, expanding hematoma, neurological deficits or hypotension.(3) Pre-operative imaging in the form of radiographs, CT scan and MRI scan help to locate the site of injury and its relation to the surrounding structures which further helps in surgical management.

MRI scans are especially helpful in localizing the nonmetallic foreign bodies. ${ }^{3}$ in our case the preoperative CT scan of neck taken helped us in localizing the foreign body. The patient was haemodynamically stable and hence a decision for early neck exploration was made. The foreign body was recovered without causing any damage to the vital structures.

\section{CONCLUSION}

Penetrating injury to the neck is an uncommon, but a potentially life threatening condition. Though the wound of entry might be inconspicuous making the injury look trivial, the underlying damage could be much more serious.(4) These injuries are to be approached in a systematic manner as described above thereby resulting in a favorable outcome.

\section{BIBLIOGRAPHY}

1. Gulia J, Yadav S, Singh K, Khaowas A. Penetrating Neck Injury: Report Of Two Cases. The Internet Journal of Emergency Medicine. 2009;6(1).

2. Stewart MG, editor. Head, face and neck trauma comprehensive management. New york: Thieme; 2005.

3. Imokawa H, Tazawa T, Sugiura N, Oyake D, Yosino K. Penetrating neck injuries involving wooden foreign bodies: The role of MRI and the misinterpretation of CT images. Auris Nasus Larynx. 2003;30(Suppl):14.

4. Hartling RP, McGahan JP, Lindfors KK, Blaisdell FW. Stab wounds to the neck: Role of angiography. Radiology 1989;172:79-82. 